\title{
Produção de sentido sobre o sintoma infantil em serviços de saúde mental
}

\author{
Production of sense on the infantile symptom in mental health services
}

Jerto Cardoso da Silva ${ }^{[a]}$, Clarissa Junqueira Lopes ${ }^{[b]}$, Jéssica Natália Canello ${ }^{[c]}$

\footnotetext{
${ }^{[a]}$ Doutor em Estudos da Linguagem (Letras) pela Universidade Federal do Rio Grande do Sul (UFGRS), professor do Departamento de Psicologia da Universidade de Santa Cruz do Sul (Unisc), Santa Cruz do Sul, RS - Brasil, e-mail: jerto@unisc.br

${ }^{[b]}$ Acadêmica do curso de Psicologia da Universidade de Santa Cruz do Sul (Unisc), Santa Cruz do Sul, RS - Brasil, e-mail: cla_jl@yahoo.com.br

${ }^{[c]}$ Acadêmica do curso de Psicologia da Universidade de Santa Cruz do Sul (Unisc), Santa Cruz do Sul, RS - Brasil, e-mail: jessicacanello@mx2.unisc.br
}

Recebido: $11 / 01 / 2011$ Received: 01/11/2011

Aprovado: $14 / 04 / 2011$ Approved: 04/14/2011

\section{Resumo}

Este trabalho visa a analisar as falas e as práticas dos profissionais de saúde referentes aos sentidos construídos sobre o sintoma nos serviços de saúde mental, nos vales do Rio Pardo e Taquari, RS, que atendem à infância. Realizamos um estudo descritivo a partir da Análise de Discurso de tendência francesa em 37 entrevistas semiestruturadas. Percebemos uma multiplicidade de sentidos atribuídos ao sintoma, mas essa polissemia é atravessada por alguns sentidos dominantes, sendo que o sintoma, apontado como uma expressão de alguma coisa ou anúncio de que algo não está bem no sujeito, o mais frequente. Outros profissionais referem que o sintoma é parte do sujeito, algo que o estrutura. Alguns ainda entendem o sintoma como tendo uma existência concreta, como algo que é visível e externo, manifestando-se então no sujeito. Observamos, nesses vários discursos, que os diferentes sentidos atribuídos ao sintoma na infância parecem apontar, de forma frequente, para as dimensões sociais e os sistemas familiares como elementos constitutivos no entendimento dos sintomas na criança.

Palavras-chave: Sintoma. Criança. Psicologia. Saúde mental.

\section{Abstract}

This paper aims to analyze the speeches and practices of health professionals regarding the senses built on the symptom in children-oriented mental health services, in the valleys of Rio Pardo and Taquari, RS. We conducted a descriptive study through the French-based Discourse Analysis in 37 semi-structured interviews. We noticed a multiplicity of senses attributed to the symptom, but this polysemy is traversed by some predominant senses, while the symptom, viewed as the expression of something or the harbinger signaling something wrong with the subject, most frequently. Other professionals have it that the symptom is part of the subject, something that structures him/her. Some understand that the symptom has its own concrete existence, as something visible and external, thus manifesting itself in the subject. In these various discourses, we observed that the different senses attributed to the symptom at childhood, on a frequent basis, seem to point to social dimensions and family systems as constitutive elements in the understanding of the symptoms in the child.

Keywords: Symptom. Child. Psychology. Mental health. 


\section{Introdução}

Este projeto tem como objetivo problematizar as falas e as práticas dos profissionais de saúde referentes ao sintoma em diferentes serviços públicos. Busca também desnaturalizar esses discursos, desvelando as condições de sua constituição, procurando dar visibilidade às produções de sentidos construídos sob determinadas condições políticas e históricas que impulsionam práticas de cuidados à saúde e seus desdobramentos. Dentro desse objetivo, este estudo busca analisar os discursos formulados sobre o sintoma por diferentes profissões na área da saúde.

As práticas de cuidado à saúde estão intimamente vinculadas ao momento histórico ao qual elas vão sendo produzidas. Ao longo do tempo, essas práticas foram sendo cooptadas às próprias condições de produção das Ciências Biomédicas, como outrora eram pelas instituições religiosas. Notamos, a partir daí, a reincidência de duas tendências no interior dessas ciências: a de veicular a saúde a um estado particular do sujeito humano, isto é, as suas particularidades e vicissitudes orgânicas ou a de atrelar, a esses componentes biológicos, as questões psicossociais na evolução ou retrocesso do estado de saúde dos sujeitos.

No dicionário Houaiss (2001), nas designações sobre o sintoma, encontramos uma polissemia de significados: diz-se de elementos que se compõem numa coincidência, num encontro ou acontecimento fortuito, ou seja, algo de uma infelicidade, de uma má sorte no encontro desses elementos. A designação é atestada desde 1661 e em vários cientificismos médicos do século XIX. Temos na rubrica da medicina, a referência a um acidente produzido pela doença, do qual se tira algum presságio ou consequência e esperanças sobre o seu processo curativo. Aparece tanto como um fenômeno subjetivo (dor, mal-estar, etc.) referido por um paciente acerca da sua doença, ou seja, o discurso sobre si, usado frequentemente para estabelecer o seu diagnóstico, quanto como à manifestação de alteração orgânica ou funcional, sentido hegemônico na atualidade.

Encontramos, a partir da Psicanálise, o sintoma como a manifestação de conflito psicológico. Primeiramente como um indicador do processo patológico, sendo o sintoma um processo de defesa. Depois como formações inconscientes, ou seja, como conflito na realização de desejo, aparecendo quando dois desejos opostos colidem na busca de satisfação, engendram uma substituição de um deles e/ou conflito permanente. Temos, então, a compulsão de repetição pela ativação da pulsão de morte (Fuks, 2008).

Para Lacan $(1998,1999)$, o sintoma é uma mensagem a se decifrar, um deciframento do saber inconsciente, particular a cada sujeito que emerge sob a forma de satisfação (gozo). Portanto, é uma expressão do inconsciente que pode ser reinserida dentro de uma trama que lhe dá sentido. Caso contrário, o sujeito pode fazer do seu corpo o suporte que encarna determinados significantes que não fazem sentido para ele. 0 Ego se apropria do sintoma e aprende a lidar com ele, passando a ser um incômodo e ao mesmo tempo uma satisfação, ou seja, uma forma de o sujeito organizar seu gozo (Dias, 2006).

Em relação à infância, torna-se necessário diferenciar o sintoma na infância e o sintoma da criança. 0 sintoma na infância é algo que não a incomoda, mas sim aos seus pais ou ao meio social em que se insere. Diferentemente do sintoma da criança, que demonstra perturbações que surgem dos conflitos inconscientes da própria criança. (Leone \& Mariotto, 2007). Salientamos ainda que o sintoma da criança emerge em condição de responder ao que existe de sintomático na estrutura familiar (Lacan, 2003).

Ao tratar da relação entre a estrutura familiar e o sintoma da criança, vê-se que existe a possibilidade de uma apropriação sintomática da criança por meio de seus fantasmas ou de um assujeitamento mortífero ao desejo do outro. A intervenção clínica pode privilegiar uma dessas vertentes: interessar-se pela questão familiar, ao interpretar a criança apenas como sintoma dos pais, ou interessar-se pela verdade do desejo do sujeito e se constituir numa prática de subjetivação. Portanto, os sentidos atribuídos aos sintomas embasam as intervenções e a forma de tratar o sujeito. Assim, não há como excluir os sentidos atribuídos pelo outro ao sofrimento do sujeito, já que o sintoma da criança é atravessado pelo discurso social. No entanto é importante reconhecer que, se o discurso dos pais funciona como uma matriz simbólica de partida, fundamental para a constituição psíquica da criança, o inconsciente infantil e seus efeitos não são um simples reflexo do inconsciente parental/social (Zornig, 2001).

Como dizem Canavêz e Herzog (2007, p. 121), não estamos em busca do sentido do sintoma, mas visamos a investigar, nas produções de sentido sobre o sintoma, o que eles têm de originalidade: 
Estamos no campo de um constante devir, de um processo dinâmico que não comporta a ideia de uma causa que forneceria a chave para a compreensão dos mistérios do sintoma. ... Se em vez da origem do sintoma pensarmos no sintoma como origem, passamos à sua dimensão inventiva, ao que se revela como original no sujeito, descortinando muitos de seus mistérios. Configura-se como igualmente importante ainda a sustentação de que o sintoma possui uma função, que ordena a vida anímica e acaba contribuindo para estruturar também as relações humanas.

\section{Método}

Realizamos a pesquisa por meio de entrevistas semiestruturadas, objetivando a uma análise qualitativa a partir da Análise de Discurso de tendência francesa. Em pesquisas qualitativas, Orlandi (1999) afirma que todo dispositivo de interpretação precisa de um artefato teórico para que se efetue. A Análise de Discurso visa à compreensão de como um objeto simbólico produz sentidos, como ele está investido de significância para e pelos sujeitos. Pêcheux (1990) propõe que, ao trabalhar o discurso, deve-se dar primado a gestos de descrição das materialidades discursivas e, ao mesmo tempo, ratificar a existência de um real específico a essa materialidade; isto é, trabalhar a materialidade linguística sem, contudo, compreendê-la como um sistema fechado em si mesmo.

Partimos, assim, da superfície linguística, as entrevistas, para chegar ao espaço discursivo, pois, pela análise dessas duas dimensões (linguística e discursiva), podemos apontar algumas regularidades e instabilidades do processo discursivo.

Pêcheux (1990) ressalta que todo discurso marca a possibilidade de uma desestruturação-reestruturação de redes e trajetos, uma agitação nas filiações sócio-históricas de identificação, sendo, inevitavelmente, atravessado pelas determinações inconscientes.

Orlandi (1998) diz que a interpretação é uma injunção, é construir sítios de significância (delimitar domínios), tornar possível gestos de interpretação. Orlandi (1995) nos lembra que, embora o texto, como unidade de análise, possa ser considerado como uma unidade inteira, ele tem relações com outros textos (existentes, possíveis ou imaginários), com suas condições de produção, com o que chamamos sua exterioridade constitutiva (o interdiscurso: a memória do dizer). Enfatiza, ainda, que o sentido sempre pode ser outro e que o sujeito (com suas intenções e objetivos) não tem o controle daquilo que está dizendo, pois ele não produz apenas um único discurso.

Com esses pressupostos, realizamos as análises dos depoimentos dos sujeitos, que formaram o arquivo principal de nosso estudo. A partir dele, selecionamos várias sequências discursivas que compuseram o nosso corpus e selecionamos algumas que se transformaram em unidades discursivas de análise. Segundo Orlandi (1999), o analista, ao delimitar o seu corpus, já está diante de um gesto de interpretação que se estende até a análise pontual das sequências. A interpretação se tece na historicidade e nos efeitos da língua, na ideologia, e na materialização dessa.

Metodologicamente, como diz Indursky (1997), construir um procedimento analítico, entre outras coisas, significa estabelecer, a partir do corpus discursivo, comparações, constatar regularidades e transformações que se apliquem ao campo discursivo de referência. Analisamos as marcas discursivas, na materialidade desses depoimentos, para tornar visível a relação entre os ditos desses sujeitos e sua imbricação nas formações discursivas sobre o sintoma.

\section{Sujeitos}

Este estudo centra suas análises nos depoimentos de profissionais de saúde que são responsáveis pelo diagnóstico nos serviços de saúde. Buscamos investigar as representações deles sobre o sintoma nesses serviços. Portanto, entrevistamos 37 profissionais de diferentes serviços públicos de saúde que se dispuseram a participar da pesquisa, sendo que sete atendiam exclusivamente crianças.

Todos os sujeitos da pesquisa assinaram um Termo de Consentimento Livre e esclarecido no qual foram orientados sobre os objetivos da pesquisa e da importância de sua participação. Os critérios de sua inclusão foram: atendimento direto ao paciente, ter ou estar cursando curso superior (estagiário) e concordar em assinar esse termo.

Analisamos os depoimentos dos sujeitos que são formados por várias sequências discursivas, constituindo o corpus discursivo dessa pesquisa. 0 nosso trabalho consiste em observar, ao longo dessas sequências, quais são os sentidos construídos por esses sujeitos, estando atentos se nesses depoimentos estamos diante do mesmo discurso e dos mesmos sentidos ou se modificam de acordo com a posição 
que esse sujeito ocupa. Assim como, quais são os sentidos interditados, quais são atravessados pelo espaço institucional (profissional) que os incorpora, ou se há falas que apontam para outras formações discursivas alheias ao que está instituído na sua formação discursiva (FD) de origem. Salientamos, a partir das palavras de Orlandi (2001, p. 19), que "não há sentido sem interpretação", estando presente tanto em quem enuncia quanto em quem analisa. Portanto, a finalidade do analista não é a de decodificar o discurso em busca da verdade, mas olhar para a produção de sentidos.

\section{Resultados e discussão}

Os discursos dos profissionais de saúde apresentam uma complexidade de reflexões e uma dispersão de sentido possivelmente produzida pela diversidade de profissões e locais pesquisados. Realizamos 37 entrevistas, entre 2008 e 2010, em serviços de saúde mental da região do Vale do Rio Pardo e Taquari, RS, das quais sete das entrevistas foram com psicólogos que referiram atender exclusivamente crianças.
A seguir, apresentamos na Tabela 1 a distribuição dos profissionais por serviços de saúde correspondente.

Os dados da Tabela 1 não representam o número total de profissionais dos serviços de saúde referidos, pois representam a participação, por adesão, na pesquisa. No entanto aproximam-se significativamente deste. Justificamos a não paridade entre o número de profissionais e locais, graças ao fato de que a equipe envolvida com o atendimento em saúde mental, foco principal da pesquisa, no hospital e exclusivamente às crianças era menor. Além dos profissionais com curso superior, resolvemos entrevistar alguns estagiários das respectivas áreas, pois eles também, conjuntamente aos seus supervisores, participam do processo de alta dos pacientes. Podemos visualizar também que a maioria dos entrevistados é do curso de Psicologia, pois um dos serviços era um serviço-escola com um grande número de psicólogos.

Apontamos, em relação ao número de profissionais por sexo, que a grande maioria dos profissionais é do sexo feminino (29), sendo apenas (8) do sexo masculino, o que corrobora a permanência da "feminização" no trabalho na área da saúde (Pastore, Rosa \& Homem, 2008).

Tabela 1 - Relação de Profissionais por Serviço de Saúde

\begin{tabular}{ccccc}
\hline $\begin{array}{c}\text { Área } \\
\text { profissional }\end{array}$ & $\begin{array}{c}\text { Número de } \\
\text { profissionais }\end{array}$ & $\begin{array}{c}\text { Profissionais } \\
\text { do Caps }\end{array}$ & $\begin{array}{c}\text { Profissionais } \\
\text { do hospital }\end{array}$ & $\begin{array}{c}\text { Profissionais do } \\
\text { serviço ambulatorial }\end{array}$ \\
\hline Enfermagem & 3 & 1 & 1 & 1 \\
Medicina & 3 & 2 & 1 & - \\
Nutrição & 2 & - & 1 & 1 \\
Psicologia & 10 & 5 & 1 & 5 \\
\hline
\end{tabular}

Fonte: Dados da pesquisa.

Na Tabela 2, encontramos os sentidos mais frequentes apontados pelos entrevistados sobre o sintoma:

Tabela 2 - Categorias mais citadas pelos entrevistados sobre o sintoma

\begin{tabular}{ll}
\hline Atendimento de crianças & Atendimento de adultos \\
\hline O sintoma como anúncio ou expressão de alguma coisa. & O sintoma como anúncio ou expressão de alguma coisa. \\
\hline O sintoma como enigma. & 0 sintoma como um fenômeno, tendo uma existência concreta. \\
& 0 sintoma como parte do sujeito/estrutura do sujeito. \\
& 0 sintoma como enigma. \\
& 0 sintoma não é algo "central". \\
& 0 sintoma como um incômodo/queixa. \\
\hline
\end{tabular}

Fonte: Dados da pesquisa. 
Percebemos, na Tabela 2, uma polissemia de sentidos sobre o sintoma graças à diversidade de profissões e locais nos quais realizamos as entrevistas.

No hospital, há uma menor diversidade de sentidos sobre o sintoma. 0 que mais aparece é o sintoma como sendo expressão de algo, anúncio, sendo que a grande maioria dos sentidos sobre sintomas estão atrelados às condições físicas, com poucas citações se referindo ao sintoma como algo que vai além do corpo. No entanto, no hospital, na relação aos demais serviços, encontramos sentidos silenciados, pois nesse local predominam os sentidos predominantemente biomédicos. Ele é tratado como tendo uma existência concreta. Embora tenhamos encontrado o sintoma pensado como uma produção, anúncio e expressão de alguma coisa, sendo um enigma que é constitutivo do sujeito, principalmente, nos discursos da Psicologia.

No serviço público não estatal, há uma diversidade muito grande de sentidos sobre o sintoma. O sentido atribuído ao sintoma com maior prevalência no serviço público não estatal está relacionado ao sintoma como anúncio ou expressão de alguma coisa. Os transtornos psíquicos são os mais mencionados, sendo mais citados os transtornos de humor, principalmente a depressão. Quando entrevistamos profissionais não psicólogos, os transtornos somáticos são os mais citados.

Notamos no Caps, uma grande diversidade de sentidos sobre o sintoma, sendo mais mencionado como parte ou estrutura do sujeito, seguido do sentido de anúncio ou expressão de alguma coisa. Também é bastante citado o sentido do sintoma como fenômeno que tem existência concreta. Os sintomas mais citados são relacionados com os transtornos psíquicos, dentre eles os transtornos de humor, sendo a depressão a mais citada, seguido dos transtornos psicóticos e, na sequência, por transtornos de ansiedade. O Caps é o local no qual pulsam uma maior heterogeneidade de sentidos sobre o sintoma.

Nas falas dos profissionais, podemos construir uma relação de sentidos mais frequentes: o sintoma "é algo a ser extinto; como expressão de alguma coisa, como anúncio; o sintoma não é algo 'central"' no tratamento do sujeito; aparece também como a produção de sentido, ou seja, algo em que a intervenção do profissionais deve fazer produzir sentido para o sujeito; o sintoma como enigma a ser decifrado; como parte constitutiva do sujeito; o sintoma como tendo uma existência concreta, como um fenômeno independente do sujeito e com uma causa externa; ou ainda, como resultado, depósito de várias situações vivenciadas pelo sujeito.

Os sentidos atribuídos pelos profissionais de saúde ao sintoma na infância não apresentam diferenças em relação aos sentidos atribuídos aos sintomas dos adultos. Ressaltamos que, dentre esses sentidos, o sintoma como anúncio ou expressão de alguma coisa é o mais citado em relação à infância. Como podemos apreciar nos recortes a seguir:

... alguns sinais, alguns indicadores de alguma dificuldade daquele paciente. ... um sinal de que alguma coisa não está legal. ... o sintoma faz esse papel de denunciar que está acontecendo alguma coisa, que tem uma dificuldade, mas por outro lado a gente também tem essa dificuldade assim de quando sai, termina o sintoma, de manter o paciente aqui. ... esse indicador, essa atitude ou esse sentimento que está disfuncional ali, quer dizer, disfuncional não está, porque ele está por um motivo, ele vem por algum motivo assim, mas que ele não está apropriado vamos dizer assim, que está sinalizando que tem alguma dificuldade, que tem algum problema; 032p.

O sintoma éo sinal de alerta da gente assim, pra própria pessoa tá sentindo e pro profissional que tá atendendo. Quando aparece um sintoma é porque alguma coisa não tá bem, alguma coisa que talvez tu ainda nem te deu conta. ... Bom, o sintoma também eu considero até por isso mesmo, acho que por um lado uma coisa saudável, quando tu consegue fazer um sintoma, porque aí tu declara que algo não tá bem e dá a possibilidade de trabalhar ... O sintoma vem a falar, entre aspas, algo que tu não tá conseguindo ver ou entender, o sintoma acho que pode ser um pedido de ajuda; 033p.

Sintoma eu acho que é uma coisa aparente, que fica mais aparente de, até porque é um sintoma, que é o que aparece de outras coisas que não estão bem, quer dizer, simboliza outras coisas que não estão bem ... simboliza alguma coisa que aquela pessoa não tá conseguindo lidar naquele momento né, até porque é um pedido assim de ajuda; $034 \mathrm{p}$.

Sintomas são sinais né, que a pessoa mostra né, que é uma denúncia que a pessoa tá fazendo que ela não tá legal, então pra mim isso são sintomas, são sinais que a pessoa tá te mostrando né, a partir do conjunto desses sintomas, e da avaliação mais aprofundada da pessoa tu tens um diagnóstico; 035p.

... na maioria dos casos, crianças que têm problemas de comportamento, falta de interesse, muitas crianças que têm uma queixa assim inicial, que não presta atenção, que só se mexe, que não tem interesse, às vezes vêm assim né, que a criança não tem interesse e, na verdade, 
ela tá com um baita de um atraso mental de dois, três anos né, ou outros casos assim por problemas emocionais também muitos associados de repente né, de separação, e problemas assim do casal né, desestruturas assim também muito bruscas, econômicas assim né, com uma frustração muito grande, então também de repente logo cai o aprendizado. ... É um indicador de que alguma coisa não tá bem, acho que sintetizando é isso né, e aí se vai a procura se é um sintoma orgânico, se é emocional, se é físico, se é mental; 037p.

... o sintoma é o que traz, mas há outras, várias coisas por trás dele. O sintoma é o que vem assim, sente, mas tem muitas outras coisas, e não é possível logo querer dar uma abafada; 001p.

Como diz Mannoni (1980, p. 73) "o sintoma é uma linguagem que nos cabe decifrar". Notamos, nas falas dos profissionais, que, em saúde mental, se busca no discurso social e não apenas na dimensão orgânica, uma resposta ao sentido dos sintomas das crianças. A autora ainda ressalta que o sintoma para uns pode ser uma solução para alguma dificuldade ou um pedido de ajuda no qual busca fazer valer sua mensagem que deve ser entendida para além de sua dimensão concreta.

Quando comparamos com os sentidos atribuídos aos sintomas nos adultos com as designações dadas aos sintomas da criança, observamos, nesses vários discursos, que os diferentes sentidos parecem apontar, de forma frequente, para as dimensões sociais e os sistemas familiares como elementos constitutivos no entendimento dos sintomas na criança. Como vemos nas citações a seguir:

... são questões né da criança, assim, até porque junta muito assim, né, tem, teve problemas físicos né, às vezes questões do nascimento, aí junta com problemas familiares, vai juntando assim né, mas é um símbolo assim de uma coisa que não tá bem, na família. 034p.

... na verdade não é um desejo da criança também né, eles vêm aqui trazidos por o adulto, pelo pai, pela escola que teve a demanda, por um médico né, então todos vêm com sintomas, e os sintomas são os mais variados né ... 036p.

... ele está estruturado internamente, uma estrutura interna e externa, familiar e interna dele assim... 036p.

... Outros casos assim por problemas emocionais também muitos associados de repente né, de separação, e problemas assim do casal né, desestruturas assim também muito bruscas, econômicas assim né, com uma frustração muito grande, então também de repente logo cai o aprendizado. ... É um indicador de que alguma coisa não tá bem, acho que sintetizando é isso né, e aí se vai a procura se é um sintoma orgânico, se é emocional, se é físico, se é mental... 037p.

Como afirma Zornig (2001), a criança é um sujeito em processo de estruturação. Não é uma entidade sem si mesma, mas faz parte de um discurso coletivo, respondendo ao que existe de sintomático nesse discurso, em especial, ao da família.

Nessa perspectiva, Sigal (2009) enfatiza que nossa própria realidade pode ser vista como produtora de patologias, por meio do consumismo desenfreado, da exigência por satisfação pulsional imediata, da falta de solidariedade, entre outros aspectos. E tudo isso, continua a autora, contribui para transformar o sujeito em objeto, embotando seus processos criativos e intelectuais, colocando-se em posição de falência. Essa evitação do mal-estar incentiva a busca de uma solução que seja capaz de reduzir ou eliminar imediatamente o sintoma, sendo esse equivocadamente tratado apenas de forma objetivável, dissimulando suas dimensões sociais (Calazans \& Lustoza, 2008).

Portanto podemos pensar, a partir dessas falas, que o sintoma não é apenas da criança, pois seus pais ou aquelas pessoas com quem convive podem também constituir e/ou sofrer com seus sintomas. A criança muitas vezes não tem consciência do seu sofrimento. Geralmente, quem sofre as consequências dos seus atos não é ela própria, mas as pessoas no seu entorno (Aberastury, 1996).

A análise desses discursos nos possibilita uma reflexão sobre as condições de produção e apreensão dos significados sobre o sintoma, o que conduz na compreensão do funcionamento, da organização e das formas de produção social do sentido (Minayo, 2004).

\section{Considerações finais}

Podemos perceber que os sentidos estão atravessados por um exterior constitutivo, ou seja, nessas diferentes profissões, formações e instituições nos quais prestam serviços (hospital, Centro de Atenção Psicossocial Infantil e de Adulto, ambulatórios e serviço público não estatal). Embora tenhamos encontrado discursos que mantêm os mesmos sentidos, notamos que novos sentidos são apresentados. 
Podemos então falar sobre uma heterogeneidade de sentidos entre os profissionais de saúde, tendo como aporte suas diferenças na formação, mas também balizada pela sua prática cotidiana nas instituições, objeto e objetivo de trabalho.

Portanto, enfatizamos que o discurso sempre mobiliza sentidos, que se constituem dentro de uma certa ordem, de uma certa organização e que se materializam nas práticas dos sujeitos, profissionais de saúde, atravessados por uma formação e instituições que não podem deixar de ser ideológicas, ideologia pensada aqui como produção de sentido. Mesmo o discurso da neutralidade é, em si, ideológico. A ideologia é constitutiva do discurso e da linguagem humana. Temos que entender que formações ideológicas são essas, ou seja, que direção os sentidos nos tomam e nos carregam em nossas práticas. Ao falar em saúde, não se está desvinculado desse pressuposto, isto é, não é por se tratar de profissões ancoradas na ciência, em especial, dentro do discurso biomédico, que elas não estejam interpeladas pela ideologia, mesmo que se aclamem pretensamente neutras e, por isso, pretensamente alheias a essa interpelação. A neutralidade é um efeito de evidência dos sentidos e, consequentemente, ideológica.

o Outro, ou seja, o discurso social, potencialmente afeta a saúde do sujeito, pois é a partir dele que balizamos o nosso próprio estado de saúde, construímos socialmente indicativos, indícios, sintomas que expressam doenças.

Enfim, as condições materiais de vida podem compor tanto estados de doença como de saúde. Salientamos, então, que o sujeito, ao se constituir a partir dos sentidos instaurados na sua relação com essa materialidade e com o outro, produz sentidos sobre o que lhe acontece e com o que acontece com o outro, pois, primordialmente, o sujeito não se dá conta dos processos que o fazem estar atrelado a situações que o adoecem ou lhe dão saúde, já que são injunções inconscientes e ideológicas. 0 sentido que se atribui, assim como o inconsciente, não é bom, saudável, ou mau, enfermo. Ele apenas produz efeitos no discurso e no corpo do sujeito, isto é, o corpo é o organismo discursivisado e, ao sê-lo, carrega sentidos. Os discursos que se produzem sobre saúde, por sua vez, têm um efeito material na vida do sujeito, pois o sujeito falante sofre o impacto da cadeia significante no seu corpo. Esse impacto pode tanto ser positivo, fazendo que ele suporte as adversidades, como pode fazê-lo padecer.

\section{Referências}

Aberastury de Pichón Rivière, A. (1996). Abordagem à psicanálise de crianças. Porto Alegre: Artes Médicas.

Calazans, R., \& Lustoza, R. Z. (2008). A medicalização do psíquico: Os conceitos de vida e saúde. Arquivos Brasileiros de Psicologia, 60(1), 124-131.

Canavêz, F., \& Herzog, R. (2007). A singularidade do sintoma: Por uma crítica psicanalítica à ideia de origem. Psicologia Clínica, 15(2), 109-124.

Dias, M. G. L. V. (2006). O sintoma: De Freud a Lacan. Psicologia em Estudo, 11(2), 399-405.

Fuks, L. B. (2008). Narcisismo e vínculos: Ensaios reunidos. São Paulo: Casa do Psicólogo.

Houaiss, A. (2001). Dicionário eletrônico Houaiss da Língua Portuguesa. Rio de Janeiro: Objetiva. Versão 1.0.

Indursky, F. (1997). A fala dos quartéis e as outras vozes. Campinas: Ed. da Unicamp.

Lacan, J. (1998). Escritos. São Paulo: J. Zahar.

Lacan, J. (1999). 0 seminário, livro 5: As formações do inconsciente. Rio de Janeiro: J. Zahar.

Lacan, J. Outros escritos. Rio de Janeiro: J. Zahar, 2003.

Leone, C., \& Mariotto, R. M. M. (2007). Controvérsias no tratamento psicanalítico com crianças: Qual o lugar dos pais? Psicologia Argumento, 25(49), 135-142.

Mannoni, M. (1980). A primeira entrevista em psicanálise. Rio de Janeiro: Câmpus.

Minayo, M. C.S. (2004). O desafio do conhecimento: Pesquisa qualitativa em saúde (8. ed.) São Paulo: Hucitec.

Orlandi, E. P. (1995). As formas do silêncio: No movimento dos sentidos. Campinas: Ed. da Unicamp.

Orlandi, E. P. (1998). Interpretação: Autoria, leitura e efeitos do trabalho simbólico (2. ed.). Petrópolis: Vozes.

Orlandi, E. P. (1999). Análise de discurso: Princípios \& procedimentos. Campinas: Pontes.

Orlandi, E. P. (2001). Discurso e texto: Formulação e circulação dos sentidos. Campinas: Pontes.

Pastore, E., Rosa, L. D., \& Homem, I. D. (2008). Relações de gênero e poder entre trabalhadores da área da saúde. Recuperado em 5 jan. 2011, em http://www.fazendo genero.ufsc.br/8/sts/ST25/Pastore-Rosa-Homem_25.pdf 
Silva, J. C. da., Lopes, C. J., \& Canello, J. N.

Pêcheux, M. (1990). Delimitações, inversões, deslocamentos. Cadernos de Estudos Linguísticos, (19), 7-24.

Sigal, A. M. (2009). Desatenção na infância: Um estudo sobre a síndrome de desatenção (ADD). In A. M. Sigal. Escritos metapsicológicos e clínicos (pp. 307323). São Paulo: Casa do Psicólogo.
Zornig, S. A. J. (2001). Da criança-sintoma (dos pais) ao sintoma da criança. Psicologia Clínica, 13(2), 119-127. 